\begin{tabular}{|c|c|}
\hline \multirow{3}{*}{ 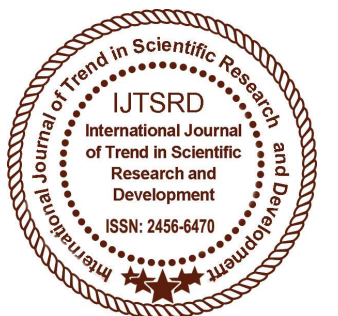 } & $\begin{array}{l}\text { International Journal of Trend in Scientific } \\
\text { Research and Development (IJTSRD) }\end{array}$ \\
\hline & International Open Access Journal \\
\hline & ISSN No: 2456 - 6470 | www.ijtsrd.com | Volume - 2 | Issue - 2 \\
\hline
\end{tabular}

\title{
Perception of Security in Mexico through Bayesian Networks
}

\author{
Carlos Ramírez \\ Sierra Sur University
}

\author{
Guillermo De la Torre-Gea \\ Sierra Sur University
}

\begin{abstract}
The present investigation shows an analysis of the perception of security by the population, using the Bayes probabilistic method, based on open data from the Survey of Victimization and Perception of Public Safety (ENVIPE). Through a Bayesian network composed of variables that are mostly interrelated, coupled with probabilistic inferences that in turn project on others, with the purpose of analyzing their probabilistic behaviors by originating actions that should be considered as preventive measures in the face of insecurity. As a result of this study, people who have home surveillance systems installed as a preventive measure, choose to change their residence, which means that this security measure has not contributed to the reduction of crime. On the other hand, most of the probabilities analyzed depend on the locality specifically since, in turn, these consist of different criminal indices. Applying the probabilistic analysis, it allowed comparing the results with current information, being coherent with the indexes issued by the different national and international organisms in relation to public security.
\end{abstract}

Keywords: Security perception, the Bayesian network, probabilistic analysis

\section{INTRODUCTION}

The social problem of insecurity and violence, are phenomena that overwhelm Mexicans with increasing force, for this reason, society has been implementing some protection measures in order to continue with their daily activities, since the perception of the part of it, is undoubtedly alarming by the figures reported daily in the various media (Koskela, 2000).

Studies conducted by the National Institute of Statistics and Geography (INEGI) through its Survey of Victimization and Perception of Public Safety (ENVIPE) reveals the main problems facing the population. In Mexico, $59.1 \%$ of the population aged 18 and over at the national level considers Insecurity and delinquency as the most important problem that afflicts their federal entity today, followed by Unemployment with $40.8 \%$ and Poverty with $31.9 \%$ as illustrates Figure 1 (Arellano, 2007; ENVIPE, 2016).

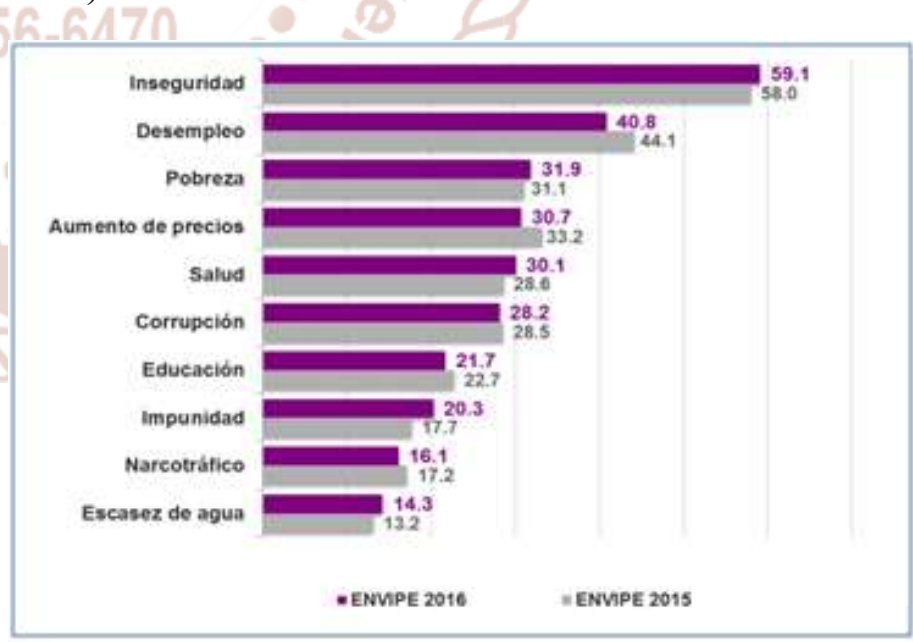

Figure 1. Main problems of the population, source: ENVIPE 2016. 
Based on a survey carried out by Semáforo Delictivo "79\% of the population indicates that in the last year security in Mexico has' worsened ', $12 \%$ reveal that' it is the same 'and only $10 \%$ say that' it has improved "(Solis, 2017). Consequently, the perception of insecurity is still very high, affecting the population, to such a degree that they suspend daily activities for fear of being a victim of some type of crime. Figure 2 shows, in most cases, an increase in the population that stopped doing some activity in 2016 compared to 2015. Consequently, this causes that preventive measures are generated by individuals in order to increase your security (Fuentes, 2003; Hempel et al., 2003; Estavillo, 2016).

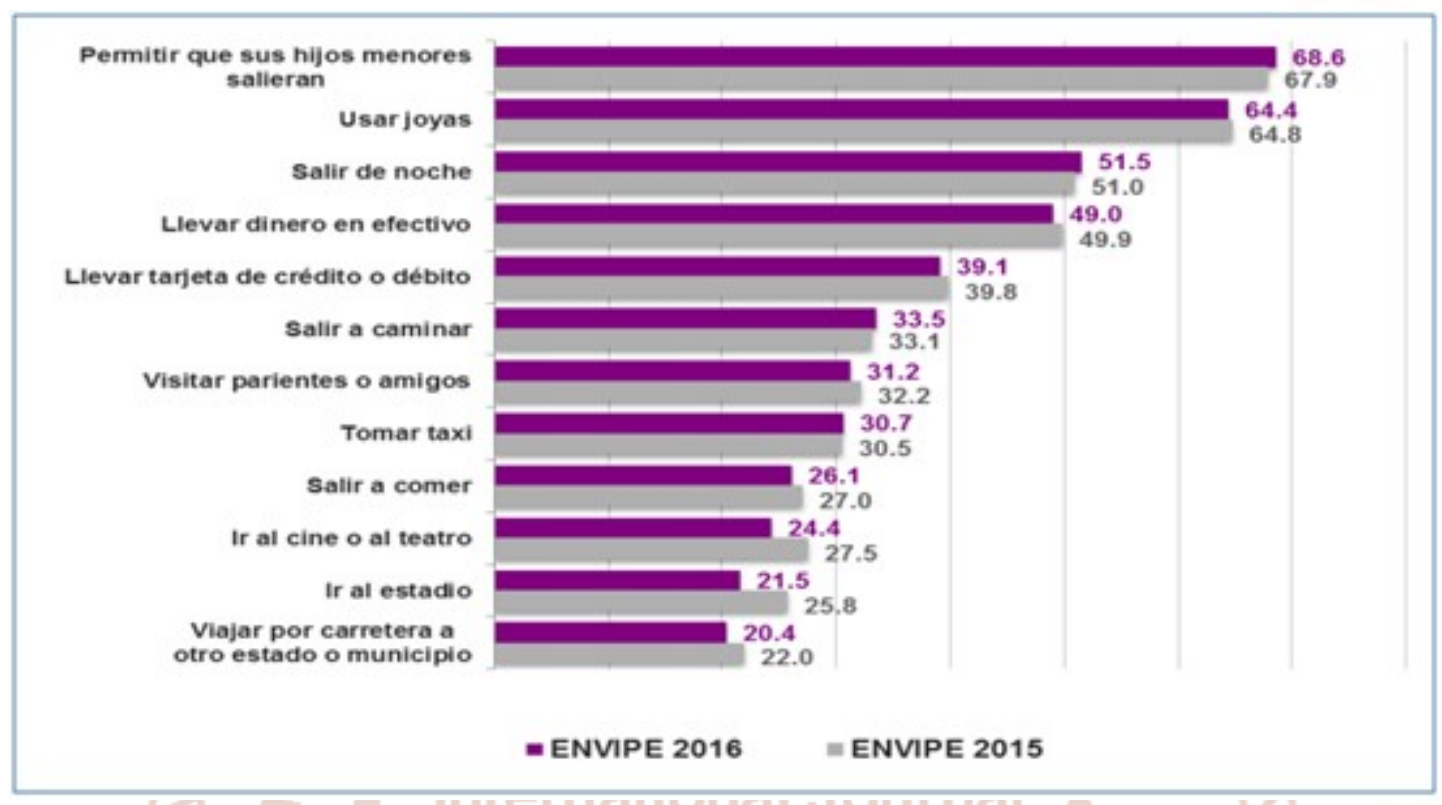

Figure 2. Population that stopped doing some activity for fear of a crime.

Therefore, the primary objective of this research is to analyze the perception of security by the Mexican population, using the Bayes probabilistic method, based on the development of a Bayesian network that interrelates the variables considered in this research that most forward is indicated, with open data of ENVIPE 2016.

\section{MATERIALS AND METHODS}

The method used in this case study is quantitative, with open data from ENVIPE 2016, using Bayes' theorem, which is defined as: "an expression of conditional probability that demonstrates the benefits obtained in estimates based on intrinsic knowledge" (Mesa et al., 2011). That is, from a previous knowledge of an initial variable, it can be inferred from the results of a second variable related to it. "The different inference methodologies can be seen as a set of formulas that are applicable in certain cases and under certain conditions" (Martínes, 2018; PascualGarcía, 2018).

For this purpose, a Bayesian classifier based on the $\mathrm{K} 2$ algorithm was used to analyze the interrelation between the studied variables, since they model a phenomenon by means of a set of variables and the relations between them (Ramírez-Ramírez, 2017; Hernández-Ríos et al., 2018). With the emergence of probabilistic networks, analyzing an uncertain problem becomes more accurate. Using Bayesian Networks, the use of probability for the treatment of uncertainty allows us to predict specific study conditions, where a large number of variables intervene.

Open data related to the subject of the study were obtained, consisting of 12 variables related to the perceptibility of the safety of residents in the main metropolitan areas of Mexico, considering the information projected by the ENVIPE 2016 survey. Work was done with around 1 million of records since each variable has approximately 85,744 data, said variables are shown in Table 1, with their corresponding values. 
Table 1. Study variables.

\begin{tabular}{|c|c|c|}
\hline Key & Variable & Values \\
\hline Metropolitan area & AREAM & Entities \\
\hline \multirow[t]{3}{*}{ Safety in the colony } & \multirow{3}{*}{ Segu-col } & s1: sure? \\
\hline & & s2: unsafe? \\
\hline & & s9: Do not know/do not answer \\
\hline \multirow[t]{3}{*}{ Security in the municipality } & \multirow[t]{3}{*}{ Seg-mun } & s1: sure? \\
\hline & & s2: unsafe? \\
\hline & & s9: Do not know/do not answer \\
\hline \multirow[t]{3}{*}{ Security in the state } & \multirow[t]{3}{*}{ Seg-estado } & s1: sure? \\
\hline & & s2: unsafe? \\
\hline & & s9: Do not know/do not answer \\
\hline \multirow[t]{2}{*}{ Frequency of thefts } & \multirow{2}{*}{ Robos-frec } & s0: It was not declared as an affirmative option \\
\hline & & s1: Yes $1 \mathrm{n} n$ \\
\hline \multirow[t]{2}{*}{ Homicide } & \multirow{2}{*}{ Homicidios $\mathrm{SCl}$} & s0: It was not declared as an affirmative option \\
\hline & & s1: Yes C $\mathrm{Cl}$ \\
\hline \multirow[t]{4}{*}{ Kidnapping } & \multirow{4}{*}{ Secuestro } & s1: Yes \\
\hline & & s2: No \\
\hline & & s3: Not applicable \\
\hline & & s9: Do not know/do not answer \\
\hline \multirow[t]{5}{*}{ Security trend } & \multirow{5}{*}{$\begin{array}{c}\text { Tendencia-seg or } \\
\text { of Trend ir } \\
\text { Reseav }\end{array}$} & s1: Will it improve? \\
\hline & & s2: Will it still be as good? \\
\hline & & s3: Will it still be as bad? \\
\hline & & s4: Will it get worse? \\
\hline & & s9: Do not know/do not answer \\
\hline \multirow{4}{*}{ Fear of going out at night } & \multirow{4}{*}{ Noche-temor } & s1: Yes \\
\hline & & s2: No \\
\hline & & s3: Not applicable \\
\hline & & s9: Do not know/do not answer \\
\hline \multirow[t]{3}{*}{ Video surveillance } & \multirow{3}{*}{ 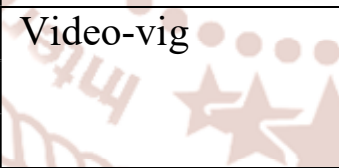 } & s1: Yes \\
\hline & & s2: No $1+>$ \\
\hline & & s9: Do not know/do not answer \\
\hline \multirow[t]{3}{*}{ Change of address } & \multirow{3}{*}{ Camb-residencia } & s1:Yes \\
\hline & & s2: No \\
\hline & & s9: Do not know/do not answer \\
\hline \multirow[t]{4}{*}{ Fight against corruption } & \multirow[t]{4}{*}{ Comb-corrup } & s1: Yes he knows \\
\hline & & s2: Does not know \\
\hline & & s3: Not done \\
\hline & & s9: Does not respond \\
\hline
\end{tabular}

In this sense, an influence diagram with open data is generated, using the Elvira program, which was created to evaluate probabilistic graphical models, specifically Bayesian networks. Elvira has its own format for coding the models, a reader-interpreter for the coded models, a graphical interface for the construction of networks, with specific options for canonical models (OR, AND, MAX, etc.), algorithms Exact and approximate (stochastic) reasoning for both discrete and continuous variables, reasoning explanation methods, decision making algorithms, 

model learning from databases, network fusion, etc.

(Diez, 2004).

\section{RESULTS AND DISCUSSION}

The Bayesian network is generated as illustrated in Figure 3, with the 12 study variables. When applying the inference as shown in Figure 4, all are interrelated with the variable AREAM = Entities, which is designated as our starting point for the majority of the analysis of the remaining 11 variables.

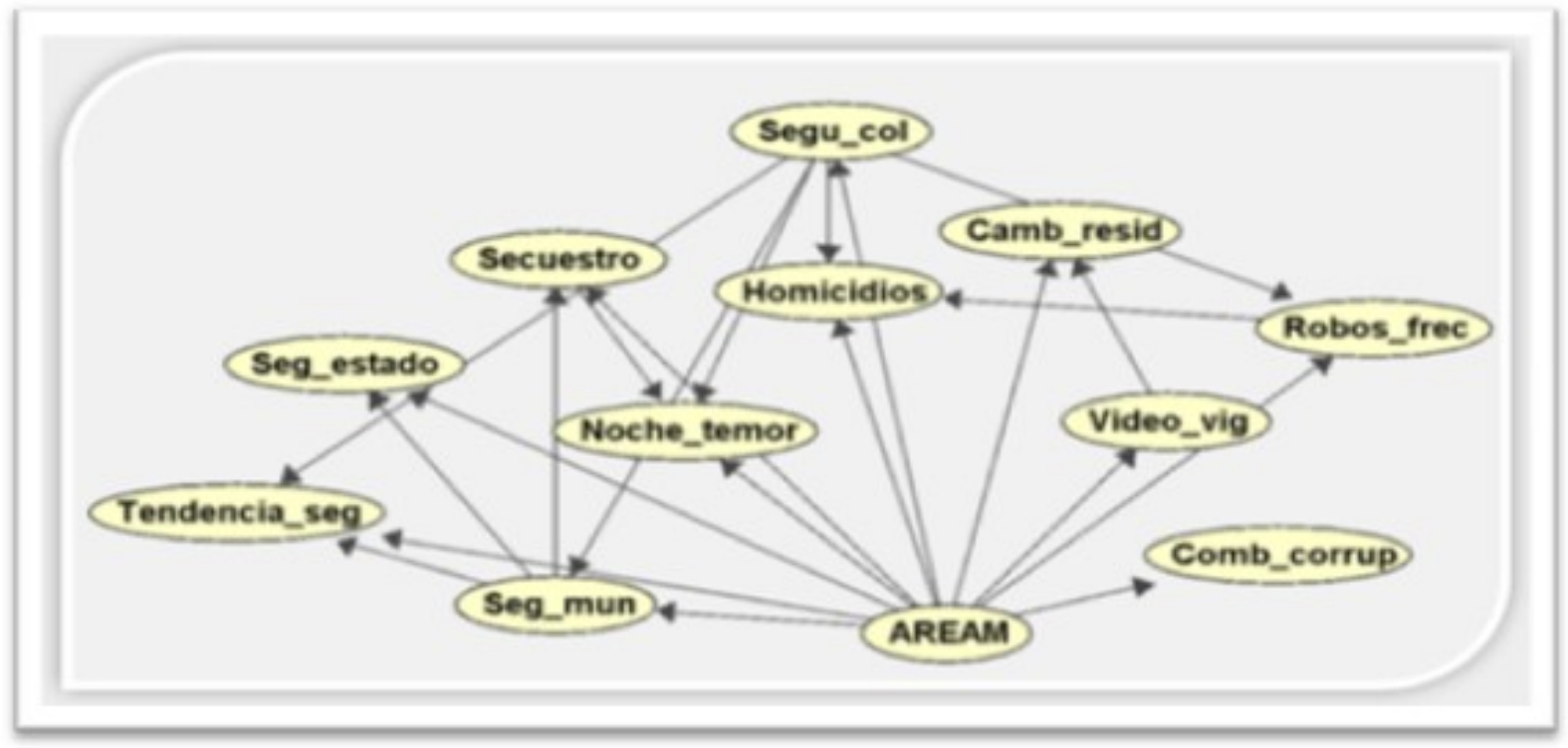

Figure 3. Bayesian Network.

Considering the variable AREAM, Mexico city represents the highest a priori probability with $12 \%$, that is, if we choose some variable from the rest of the group, it follows that it will be more likely that said locality will be involved in any other variable of the rest of the group.

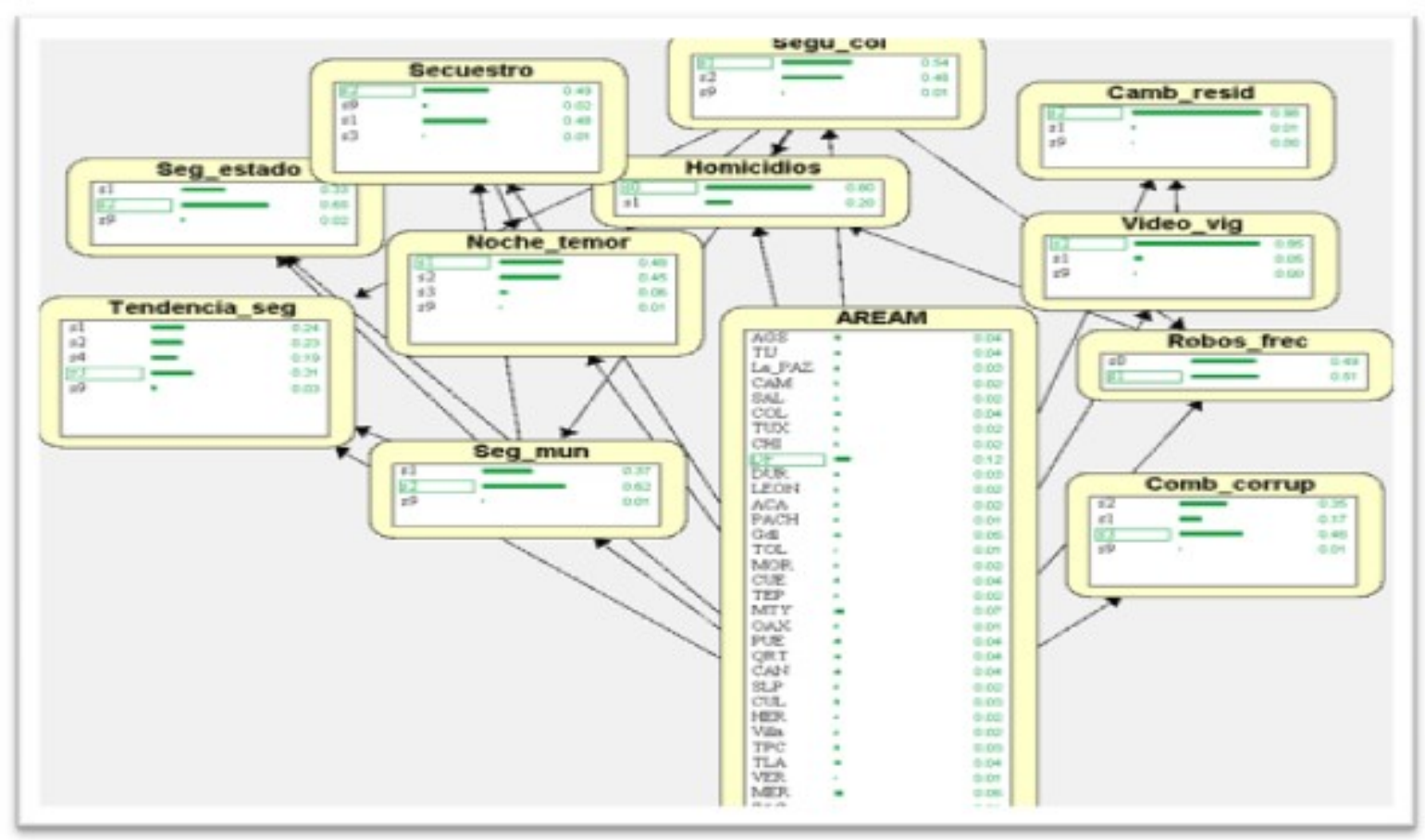

Figure 4. Inferences. 
The following cases have to do with the degree of perceptibility of the population with respect to the 'security in their colony', in this case, when interconnecting with the variable 'security in municipality' and this in turn with 'security in the state ', the a priori behavior of the variable' security in the colony 'is $46 \%$, however, when analyzing the a posteriori probability in s2 the same variable, the probabilities of the variables' municipality security' and 'security state' increased its values s2's with $85 \%$ and $79 \%$ respectively, which means that greater insecurity is perceived, as illustrated in Figure 5. Similarly, the variable 'fear night' also increases to $60 \%$ probability, to its once a $52 \%$ probability that the individual is the victim of a 'kidnapping' and as regards 'homicides'. When the population feels 'insecure in their colony', the network shows a $13 \%$ probability that a homicide will occur.

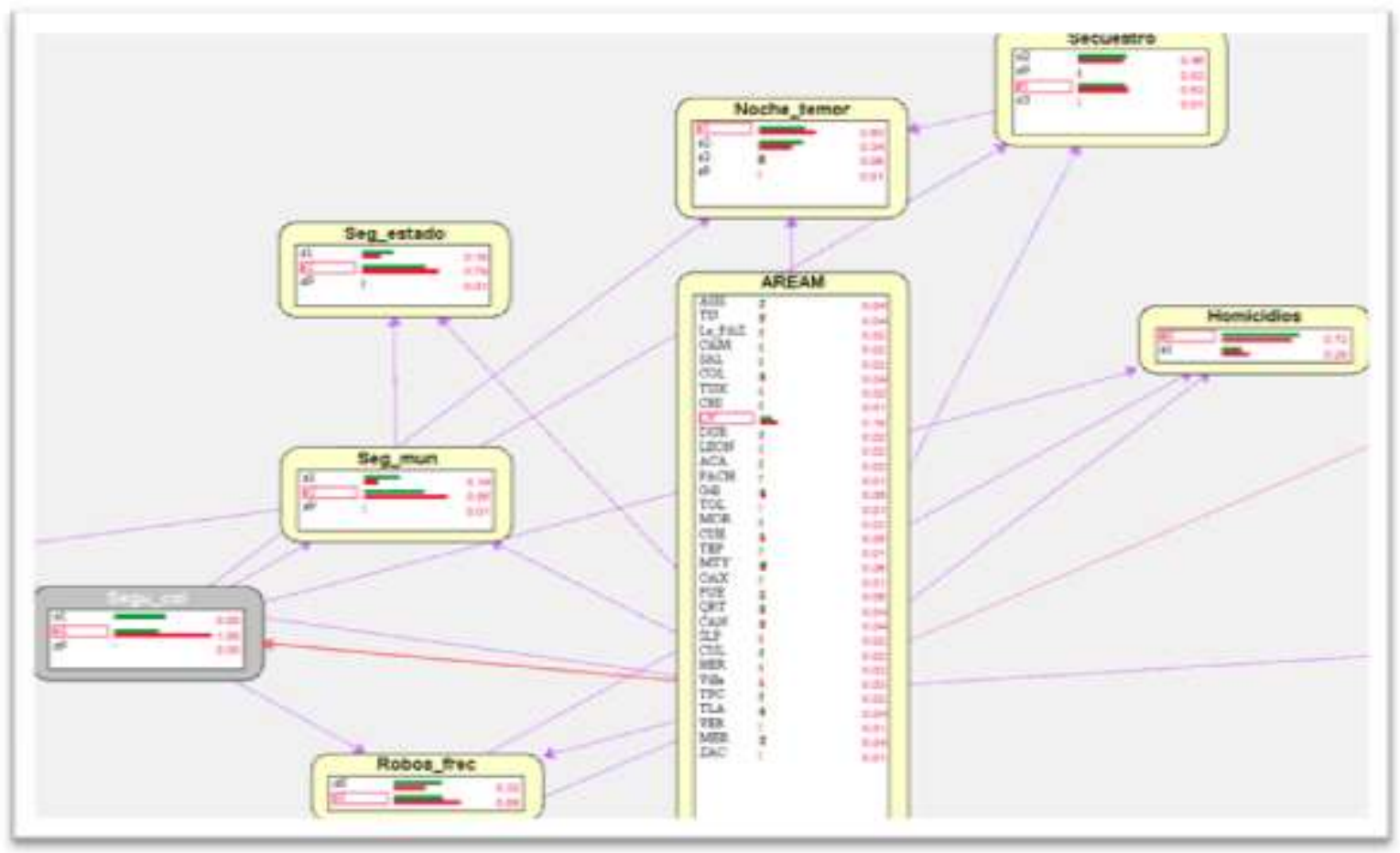

Figure 5. Bayesian network security in the colony a posteriori s2.

It is appropriate to indicate that 'security in the colony' has a strong inference of the variable AREAM as can be seen in figure 5, coupled with this, the Organization for Economic Cooperation and Development (OECD) indicates that "Mexico is the worst place to feel safe walking alone at night among member countries. " (Solís Arturo, 2017). However, when analyzing the variable 'colony security' a posteriori, the probabilities of the variable 'security state' continue greater $\mathrm{s} 2$ than $\mathrm{s} 1$ which means that greater insecurity is perceived at the state level as illustrated in Figure 6. However, the value of 'fearful night' remains with a 36\% chance of being afraid of going out at night and with a $45 \%$ chance of being a victim of a homicide. Based on these results, where the probabilities are very high and there is a strong relationship between variables, the population perceives insecurity in their current residence, causing increasing social uncertainty. 


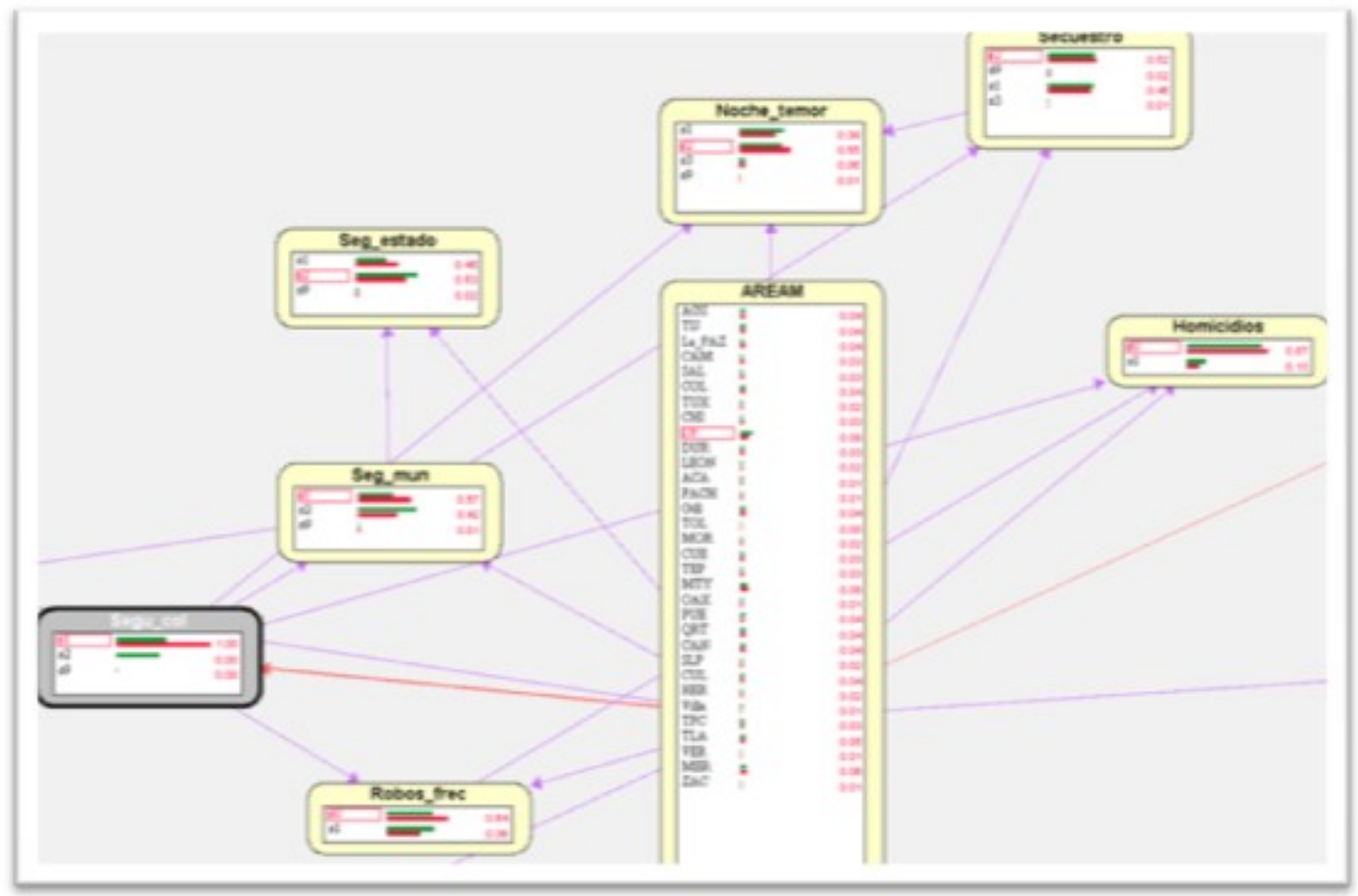

Figure 6. Bayesian network security in the colony a posteriori s1.

As a consequence of the above, the INEGI through the National Survey of Urban Public Safety (ENSU), indicates that "the majority of the Mexican population considers that living in their city is insecure." (The Economist, 2017s.p). Now, when analyzing the variable 'homicides', as can be seen in Figure 7 where it relates to: metropolitan area 'AREAM', security in the colony 'Segucol', and frequency of thefts 'Theft frequency'; In this sense, by indicating the a posterior probability of $\mathrm{s} 1$ in 'homicides', the relationship exercised by 'AREAM' with respect to the D.F is greater than the rest of the entities, since it represents $15 \%$ of the posterior probability. In relation to the posterior probability of a homicide occurring in the following entities are: Guadalajara with 8\%, Monterrey 6\%, Cuernavaca 6\%, Puebla 4\%, Acapulco 4\%, Baja California Sur 04\%, Tijuana 4\%, Colima 4\%, San Luis Potosí $03 \%$ and Culiacán $03 \%$.

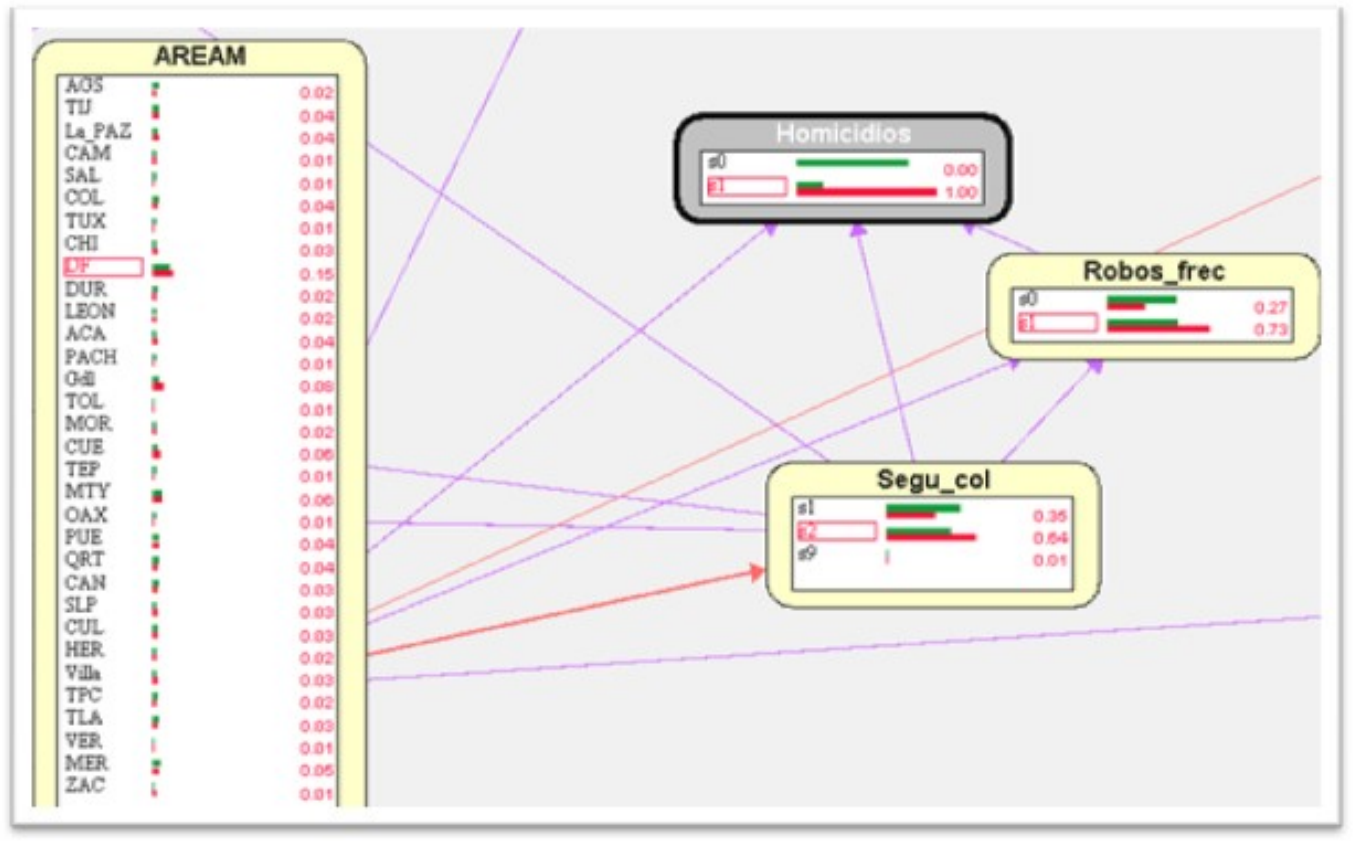

Figure 7. Bayesian network homicides s1 a posteriori. 
On the other hand, a recent analysis conducted by the Mexico Peace Index, "the 5 least peaceful states are indicated, which include: Guerrero, Colima, Sinaloa, Baja California Sur and Baja California Norte", based on the reported records with higher criminal index. (The financial, 2017, s.p). So the previous analysis through the Bayes network does not go far from the current situation to keep practicing the same entities with data for 2016, compared with information of 2017. Regarding the fight against corruption, we see that the a priori probability we have s3 in $48 \%$ and $35 \% \mathrm{~s} 2$, when analyzing the result a posteriori s3, this last one conserves the greater part of probability in comparison with s2, so that the majority of the population indicates that it has not made the fight against corruption.
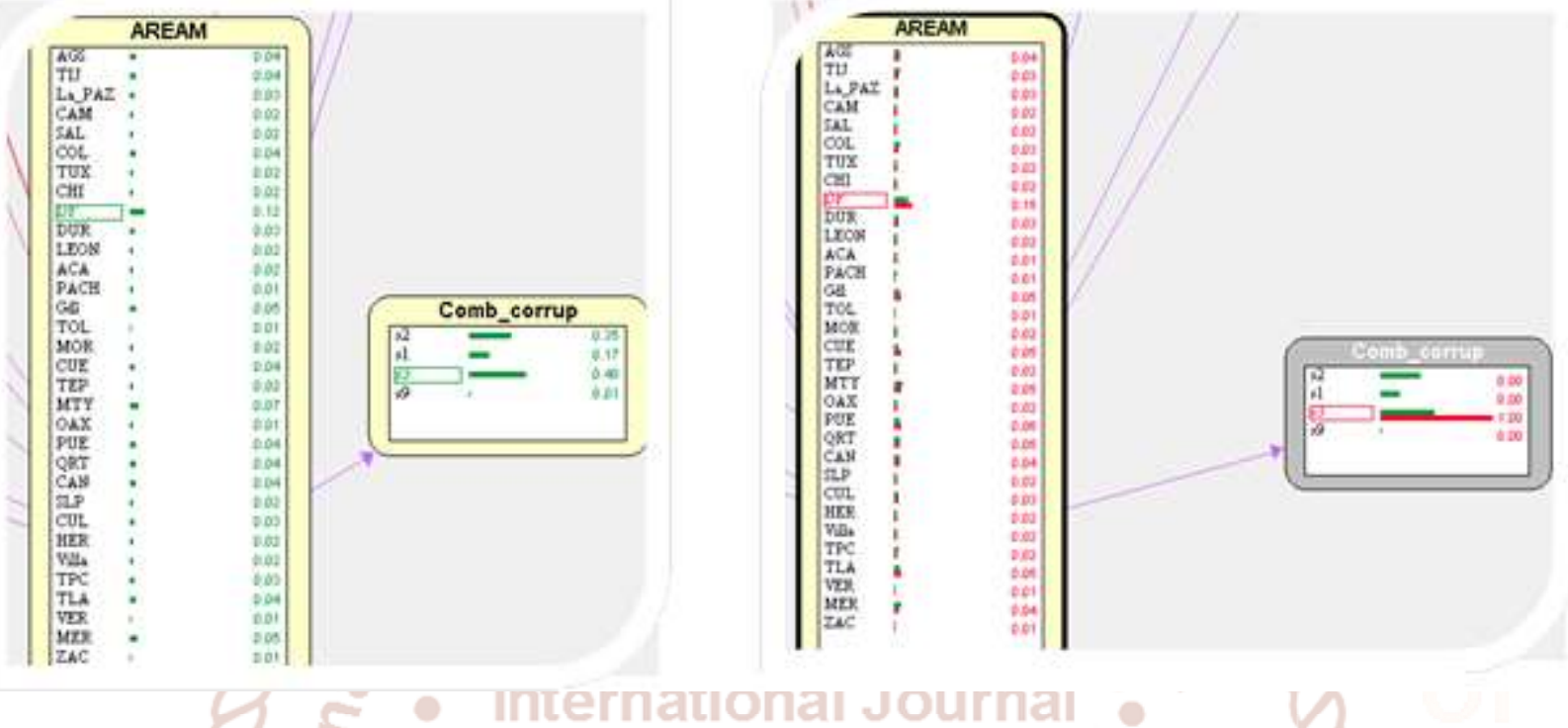

Figure 8. Bayesian network fights corruption s3 a priori and a posteriori.

In relation to the analysis of the variable 'comb_corrup' there has not been a relevant advance, on the contrary, "Mexico has the worst performance in security and fight against corruption within the 35 countries that make up the OECD". (Solís Arturo, 2017, s.p). It can be seen in Figure 9 clearly the contrasts of the corruption indexes compared with other member countries, where the zero index is the most corrupt and 100 least corrupt.

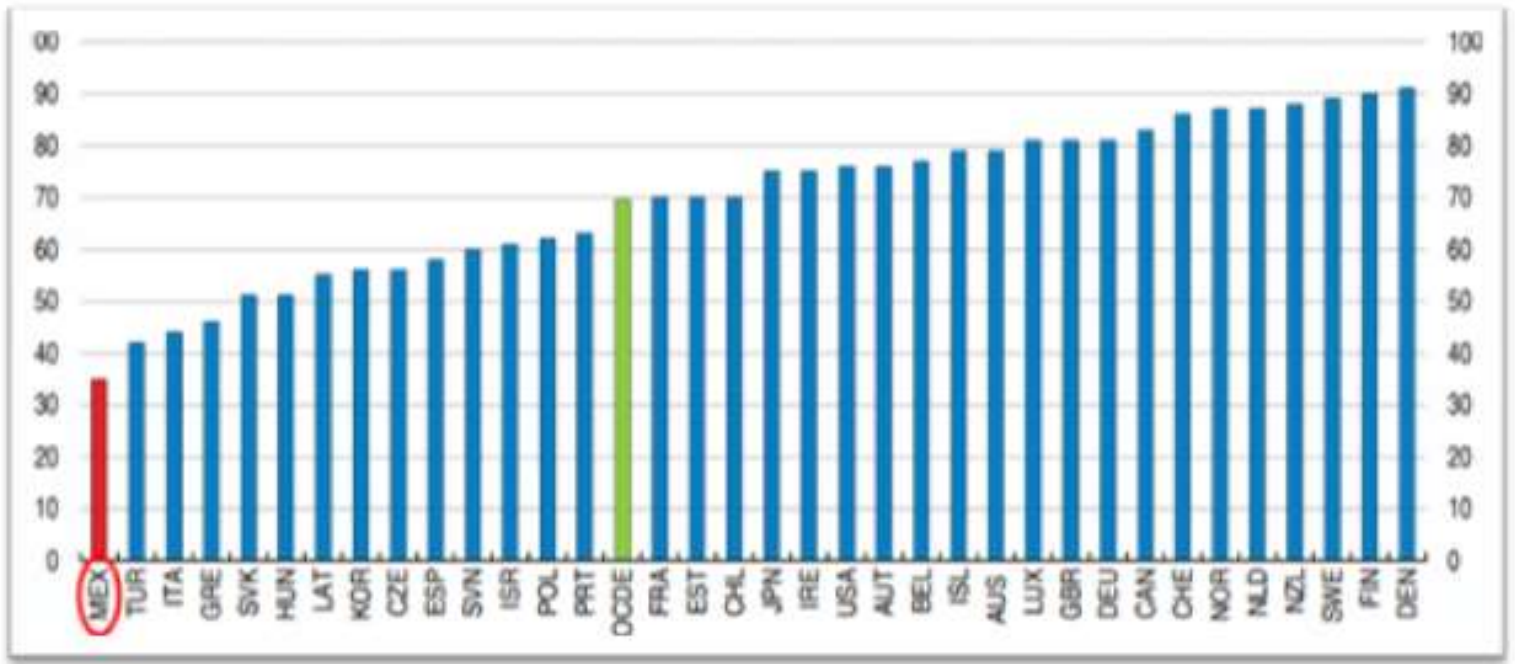

Figure 9. Mexico with the lowest performance in corruption among the OECD countries.

Finally, the analysis of the last two variables 'video-vig' and 'Camb-resid', derived largely from the perception of the population with regard to security and that in some way, gives rise to an action in consequence. Two of the actions of interest, in this case, is the implementation of surveillance cameras and the change of residence, as preventive measures in the face of the imminent insecurity that is experienced with greater intensity in certain regions of the country. 
Consequently, the study of the variable 'video-vig' in a priori presents a probability of 5\% in s1, while 'campresid' in s1 only $1 \%$, not in a posteriori, the second the s1 changes to $4 \%$, this means that since it has a surveillance camera as a preventive measure, it follows that $4 \%$ is the a posteriori probability that it changes residence due to insecurity and that it is a resident of Mexico City. with 14\%, Monterrey 8\%, Puebla 6\% and Baja California Sur 4\%, as seen in figure 10. Now, s2 a posteriori of the same variable 'video-vig', the s2 of 'camb-resid' is of $99 \%$ probability To illustrate this behavior we have Table 2 .

Table 2. Residence effects, given the video surveillance condition a posteriori.

\begin{tabular}{|l|l|l|l|}
\hline Probability & Variable & Description & Effect in variable Camb-resid \\
\hline A posteriori & Video-vig & Without & $99 \%$ no change \\
\cline { 4 - 4 } & & camera & $1 \%$ change \\
\hline A posteriori & Video-vig & With camera & $94 \%$ no change \\
\cline { 4 - 4 } & & & $4 \%$ change \\
\hline
\end{tabular}
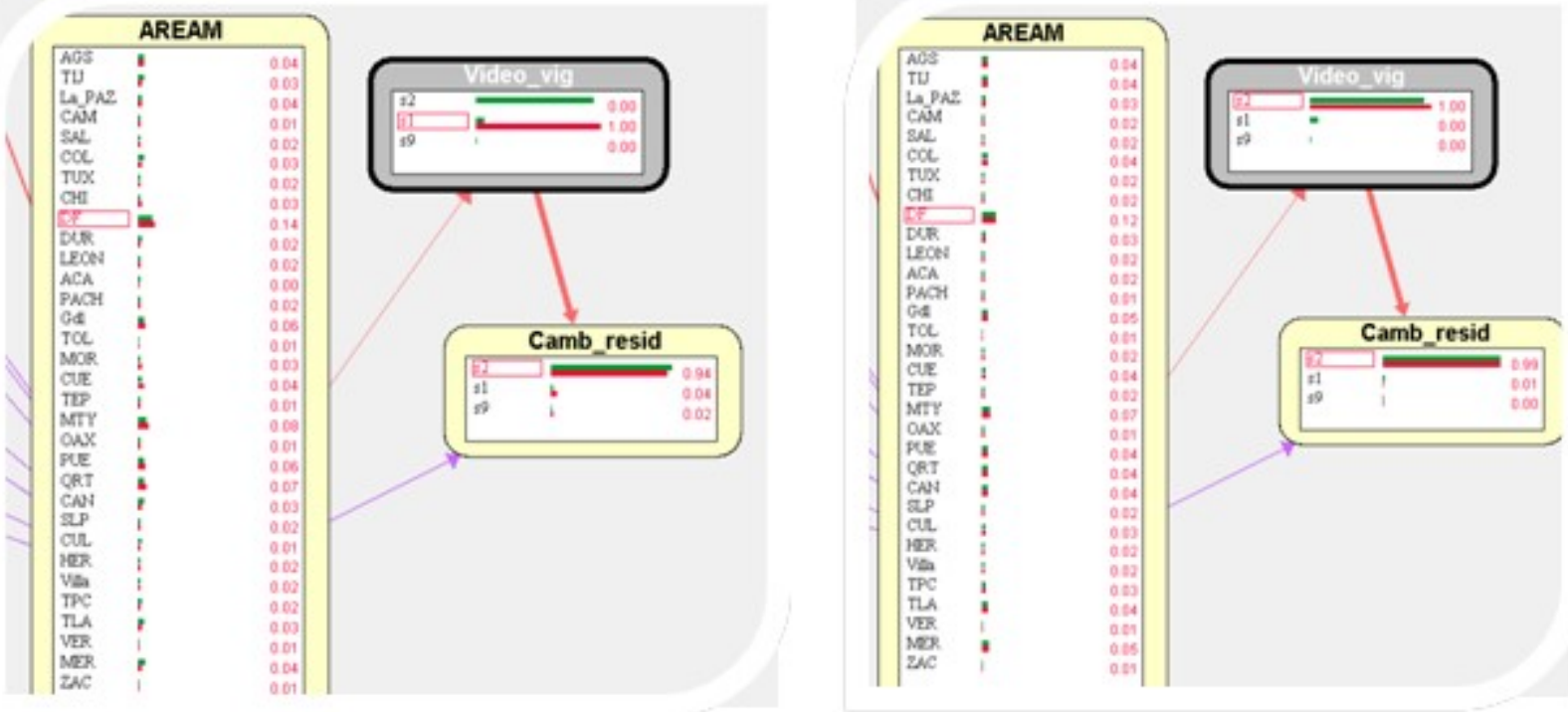

Figure 10. Bayesian network video surveillance with s1 and s2 a posteriori.

Derived from the previous table, it would be expected that the people who have in their homes implemented surveillance camera systems as a preventive measure, the probabilities of opting to change residence, should be lower than those without cameras installed, however, it happens the opposite, which means that this security measure has not contributed to the reduction of the crime.

\section{CONCLUSION}

The situation of the country depends to a great extent on the progress that is made in covering the fundamental elements that society demands its wellbeing, starting from the specific, since based on the analysis carried out, it is clearly observed that local conditions affect with greater influence perceiving greater fear on the part of the population.
On the other hand, most of the probabilities analyzed depend on the locality specifically since, in turn, these consist of different criminal indices and that undoubtedly require urgent attention by the corresponding authorities. Finally, crimes of minor and greater impact continue to increase, such as homicides, kidnappings, robberies and other acts, as observed in the different cases of analysis, manifested in the perception of the population. When applying the probabilistic analysis, it allowed comparing the results with current information, being coherent with the indexes issued by the different national and international organisms in relation to public security in Mexico. 


\section{REFERENCES}

1) Arellano, E. (2007). Políticas públicas eficaces en el combate a la delincuencia. Ciudad de México: MC editores.

2) Botello, A. (2010). Video-vigilancia del espacio urbano: tránsito, seguridad y control social. Andamios; 7(14); 263 - 286.

3) ENVIPE (2016). Recuperado through: http://www.beta.inegi.org.mx/contenidos/proyecto s/enchogares/regulares/envipe/2016/doc/envipe20 $16 \_$presentacion_nacional.pdf

4) Estavillo, M. (2016). Retos de la seguridad pública en ciudades inteligentes. Ciudad de méxico: IFT.

5) Fuentes, D. (2003). Políticas públicas y seguridad ciudadana: la violencia como problema público. Estudios Fronterizos, 13-31.

6) Hempel, L., and Töpfer, E. (2009). The Surveillance Consensus: Reviewing the Politics of CCTV in Three European Countries. European Journal of Criminology 6(2), 157-177.

7) Hernández-Ríos, M.E.; Fernández-Tapia, Joselito; De la Torre-Gea, Guillermo. (2018). Bayesian analysis as a method to determine the limitations and advances of e-Justice. . International Journal of Trend in Scientific Research and Development. 2(2); $117-122$.

8) INEGI (2016) through: http://www.inegi.org.mx/saladeprensa/boletines/2 016/especiales/especiales2016_09_04.pdf
9) Koskela. (2000). The gaze without eyes: videosurveillance and the changing nature of urban space. Progress in Human Geography, 243-265.

10) Martínez, E. and De la Torre-Gea, G. (2018), Analysis of the ICT user profile for e-government through Bayesian networks. International Journal of Trend in Scientific Research and Development. 2(2); 97 - 102.

11) Mesa Páez, Rivera Lozano y Romero Dávila Jesús Andrés (2011). Descripción general de la Inferencia Bayesiana y sus aplicaciones en los procesos de gestió, through: http://www.urosario.edu.co/Administracion/docu mentos/investigacion/laboratorio/miller_2_2.pdf

12) Pascual-García, E. and De la Torre-Gea, G. (2018). Bayesian Analysis to the experiences of corruption through Artificial Intelligence. International Journal of Trend in Scientific Research and Development. 2(2); 103 - 107.

13) Ramírez-Ramírez, R.; De la Torre-Gea, G. (2017). Analysis of Public Information Requests in eGovernment through Bayesian Network Models. Journal of Scientific and Engineering Research. 4(12); 424-432.

14) Solís A. (2017). México, el país con la peor seguridad y corrupción de la OCDE. Recuperado ele/17 de septiembre de 2017, through: https://www.forbes.com.mx/mexico-el-peor-paisen-seguridad-y-corrupcion-de-la-ocde/

15) Thiago J. (1991). Seguridad nacional y desarrollo, Diplomado de Análisis Político, México, Colegio de México, 40. 